\title{
Interstrain differences in the expression and activity of Cyp2a5 in the mouse liver
} CrossMark

\author{
Katia S. Poça, Thiago E. M. Parente, Lucas F. Chagas, Bruna S. Leal, Hellen S. Leal, Francisco J. R. Paumgartten
} and Ana C. A. X. De-Oliveira*

\begin{abstract}
Background: Cytochrome P450 2A5 (Cyp2a5), a mouse enzyme orthologous of human CYP2A6, catalyzes a number of toxicologically important reactions, including the metabolism of nicotine, aflatoxin B1, and several other xeno- and endobiotics. Cyp2a5 expression is complex and not yet fully understood. We investigated inter-strain differences in the activity and mRNA expression of hepatic Cyp2a5. Cyp1a1/2 and Cyp2b9/10 activities were evaluated for comparative purposes. Data on the interstrain differences in the expression and activity of Cyp2a5 are important to select a suitable mouse model for studying CYP2A6-mediated metabolism.

Results: Activity of Cyp2a5 (coumarin 7-hydroxylase) was highest in DBA-2 and DBA-1, intermediate in B6D2F1 (hybrid) and low in the remaining strains (C57BL/6, C57BL/10, CBA, BALB/CAn, SW). Contrasting with the activity, background levels of Cyp2a4/5 mRNA did not differ between high- and low-activity murine strains. Phenobarbital (PB, $80 \mathrm{mg} / \mathrm{kg}$ body weight/day $\times 3$ days, i.p.) increased Cyp2a5, Cyp1a1/2 (ethoxyresorufin-O-deethylase) and Cyp2b9/10 (bezyloxyresorufin-O-debenzylase) activities while only Cyp2a5 was enhanced by pyrazole (PYR, $100 \mathrm{mg} / \mathrm{kg}$ body weight/day $\times 3$ days, i.p.). Inductions of Cyp2a5 activity by PYR and PB were accompanied by increases of Cyp2a4/5 mRNA. PYR and PB did not upregulate heme oxygenase-1 (hmox-1) mRNA expression in any strain, a finding that is apparently at odds with the notion that Cyp2a5 and hmox-1 inductions are coordinated events.

Conclusions: Since background levels of Cyp2a4/5 gene transcripts of high-activity strains did not differ from those of low-activity mice, distinct constitutive activities did not result from different transcription rates and/or mRNA half-lives. Results therefore suggested that interstrain differences in constitutive activity of Cyp2a5 possibly arise from distinct translation efficiencies, protein half-lives and/or enzyme kinetics toward the substrate. Data from this study indicated that all tested strains are suitable models for studying toxicants that are substrates for human CYP2A6; DBA2, DBA-1 and the hybrid B62DF1, however, have the advantage of presenting high constitutive activities of Cyp2a5.
\end{abstract}

Keywords: Cyp2a4, Cyp2a5, Heme oxygenase, Liver toxicity, Coumarin 7-hydroxylase

\section{Background}

The cytochrome P450 2A gene subfamily $(C Y P 2 A)$ encompasses 23 genes and pseudogenes, including four genes identified in mice (Cyp2a4, Cyp2a5, Cyp2a12 and Cyp2a22), three in rats $(C Y P 2 A 1, C Y P 2 A 2$ and $C Y P 2 A 3)$ and three in humans $(C Y P 2 A 6, C Y P 2 A 7$ and CYP2A13) [1]. Mouse Cyp2a5 is orthologous of rat CYP2A3 and human CYP2A6. Among all members of

\footnotetext{
*Correspondence: ana.oliveira@ensp.fiocruz.br

Laboratory of Environmental Toxicology, Department of Biological Sciences, National School of Public Health, Oswaldo Cruz Foundation, FIOCRUZ, Av. Brasil 4036, Rio de Janeiro, RJ 21040-361, Brazil
}

CYP2A subfamily, human CYP2A6 (and also CYP2A13) and mouse Cyp2a5 are most similar regarding tissue distribution and substrate specificity. Both CYP2A6 and Cyp2a5 are expressed in the olfactory mucosa, other tissues of the respiratory tract, oesophagus and the liver. Moreover, Cyp2a5 shares many pharmacoand toxicologically important substrates with CYP2A6 including drugs, coumarin, nicotine, cotinine, aflatoxin $\mathrm{B} 1$, the nicotine-derived nitrosamine ketone (NNK), $\mathrm{N}$-nitrosodiethylamine, other xenobiotics and some endogenous compounds (steroid hormones, heme and bilirubin) [2, 3]. Cyp2a5 gene is expressed in the liver and 
in extra-hepatic tissues (e.g., olfactory mucosa, kidneys, lungs, brain, small intestines), and its activity and expression in the liver is female-predominant $[2,3]$.

Regulation of Cyp2a5/CYP2A6 expression is complex and not yet fully understood. Cyp $2 a 5$ is induced by a variety of structurally unrelated chemicals (e.g., metals, pyrazole, phenobarbital) and it can be either up- or down-regulated by pathophysiological conditions such as infections, liver cancer and inflammatory stimuli [2, 4-9]. Hypotheses have been advanced on the involvement of liver injury, oxidative and endoplasmic reticulum stress and perturbations of heme homeostasis in the over-expression of liver Cyp2a5/CYP2A6. The mode by which liver pathological conditions regulate Cyp2a5/ CYP2A6 expression and activity, however, remains to be elucidated.

Strain differences in the constitutive activity of coumarin 7-hydroxylase $(\mathrm{COH}$, a marker for Cyp2a5 activity) and coumarin metabolism have been reported and the activity recorded in the DBA-2 mice is generally higher than that found in other strains [10-12]. Mouse $\mathrm{COH}$ activity has an additive mode of inheritance due to the presence of two alleles at the Cyp2a5 gene locus on chromosome 7 , one for high activity and the other for low activity $[10,13,14]$.

This study was designed to investigate interstrain differences in the constitutive activities of Cyp2a5, Cyp1a1/2 and Cyp2b9/10, and Cyp2a5 mRNA expression in the mouse liver. To the authors' knowledge, no previous study has investigated differences between murine strains in the expression of Cyp2a4 or Cyp $2 a 5$ genes in the liver. Additionally, we investigated whether the upregulation of Cyp2a 5 activity and expression by known inducers (pyrazole and phenobarbital) was necessarily associated with clinical manifestations of liver damage and enhanced expression of heme oxygenase-1 (hmox1). Data from this study are expected to be of help for selection of a suitable mouse model in toxicological studies dealing with xenobiotic compounds metabolized by Cyp2a5/CYP2A6.

\section{Methods}

\section{Animals}

Female mice, 8-10 weeks old, from the Oswaldo Cruz Foundation (FIOCRUZ) breeding stock (Swiss Webster, BALB/cAn, C57BL/6, C57BL/10, CBA, DBA-1, DBA2 , and the F1 hybrid of C57BL/6 female and DBA-2 male, B6D2F1) were used. Six mice of the same strain were housed per cage (standard plastic cage with stainless steel cover lids) and white wood shavings were used as bedding. The animals were maintained under controlled environmental conditions $(12 \mathrm{~h}$ light/12 h dark cycle, lights on from 7 am to $7 \mathrm{pm}$; room temperature of $23 \pm 2{ }^{\circ} \mathrm{C}$ and relative humidity of approx. $70 \%$ ) with free access to a commercial rodent diet (Nuvital CR1, Nuvilab $^{\circledR}$, Curitiba, PR, Brazil) and filtered tap water. The research project was approved by the "Ethics Committee on the Use of Animals of the Oswaldo Cruz Foundation" (CEUA-FIOCRUZ). All procedures were conducted in accordance with Brazilian animal protection and welfare legislation and international guidelines [15].

\section{Chemicals}

Benzyloxy-, ethoxyresorufin, coumarin, EDTA, pyrazole, Bradford reagent, BSA, $\beta$-NADP, glucose- 6 -phosphate, glucose-6-phosphate dehydrogenase, resorufin, umbelliferone and glycine were from Sigma Chemical Co (St. Louis, MO, USA). Phenobarbital (Fenocris ${ }^{\circledR}$ ) was from Cristália Produtos Químicos Farmacêuticos LTDA (São Paulo, Brazil). All other chemicals used in the experiments were of high analytical grade.

\section{Treatment}

Mice received intraperitoneal (i.p.) injections of pyrazole (PYR, $100 \mathrm{mg} / \mathrm{kg}$ body weight/day), phenobarbital (PB, $80 \mathrm{mg} / \mathrm{kg}$ body weight/day) or phosphate buffered saline solution only (vehicle-control group, $10 \mathrm{~mL} / \mathrm{kg}$ body weight/day) for 3 consecutive days, and were euthanized by cervical dislocation $24 \mathrm{~h}$ after the last injection. Blood was taken from the retro orbital sinus immediately before the cervical dislocation. Animals were always treated and killed between noon and 2:00 pm. Mice $(\mathrm{N}=18$ of each strain) were allocated at random ( $\mathrm{N}=6$ per group) to one of the treatment groups (control, PYR and PB).

\section{Preparation of liver microsomes}

After euthanasia, livers were quickly removed, freed from fat and extra tissue, weighed and frozen in liquid nitrogen. Liver microsomal fraction (LMF) was prepared essentially as described by De-Oliveira et al. [16], except for using Tris $(100 \mathrm{mM})-\mathrm{KCl}(150 \mathrm{mM})$ buffer $(\mathrm{pH} 7.4)$ instead of sucrose solution. LMF was aliquotted in cryogenic tubes that were stored in liquid nitrogen until further use. Protein concentration of LMF was determined by the method of Bradford [17] adapted to a multi-well plate spectrophotometer reader (Spectramax Plus ${ }^{\circledR}$, Molecular Devices, USA).

\section{Enzyme activities \\ Coumarin 7-hydroxylase}

Coumarin 7-hydroxylase activity $(\mathrm{COH}$, a marker for Cyp2a5-catalyzed activity) was assayed essentially as reported by van Iersel et al. [11] with a few modifications: assay tubes (final volume of $0.5 \mathrm{~mL}$ ) contained $50 \mathrm{mM}$ Tris buffer $\mathrm{pH} 7.4,10 \mu \mathrm{M}$ coumarin and $0.8 \mathrm{mg} / \mathrm{mL}$ of protein. After a 3 min pre-incubation of coumarin and 
microsomal protein, the reaction was initiated by addition of a NADPH regenerating system $(0.5 \mathrm{mM} \beta$-NADP, $10 \mathrm{mM}$ glucose 6 -phosphate, $0.5 \mathrm{U} / \mathrm{mL}$ glucose 6 -phosphate dehydrogenase and $10 \mathrm{mM}$ magnesium chloride). Reaction was carried out for $10 \mathrm{~min}$ at $37^{\circ} \mathrm{C}$ with shaking until being stopped by the addition of $2 \mathrm{~N} \mathrm{HCl}$ to assay tubes. The reaction product, umbelliferone, was taken to tubes containing a $1.6 \mathrm{M}$ glycine- $\mathrm{NaOH}(\mathrm{pH} 10.4)$ solution and transferred to quartz cuvettes for fluorescence measurement in a spectrofluorimeter (Shimadzu RF5301PC). The equipment parameters were set as follows: excitation at $355 \mathrm{~nm}$, emission at $460 \mathrm{~nm}$ and band slit width at $3 \mathrm{~nm}$. A standard curve of umbelliferone was run in parallel with each assay.

\section{Alkoxy-resorufin-O-dealkylases}

Benzyloxy- (Cyp2b9/10) and ethoxy- (Cyp1a1/2) resorufin-O-dealkylases (BROD and EROD, respectively) were assayed in 96-well microplates as described by Kennedy and Jones [18] with some modifications. The final concentrations of components in the reaction were $5 \mu \mathrm{M}$ substrate (benzyloxy- or ethoxi-resorufin), $0.25 \mathrm{mM}$ $\beta$-NADP, $5 \mathrm{mM}$ glucose 6 -phosphate, $0.5 \mathrm{U} / \mathrm{mL}$ glucose 6-phosphate dehydrogenase and $2.5 \mathrm{mM}$ magnesium chloride. A constant amount of microsomal protein $(0.025 \mathrm{mg})$ was added to each well. After a $10 \mathrm{~min}$ reaction time at $37^{\circ} \mathrm{C}$ in a shaker water-bath, acetonitrile was added to each well. The product of the reaction (resorufin) was measured using a fluorescence plate reader (Spectramax Gemini XS ${ }^{\circledR}$, Molecular Devices, USA) with excitation and emission wavelengths set at $530 \mathrm{~nm}$ and $590 \mathrm{~nm}$, respectively.

\section{Alanine and aspartate aminotransferases}

Serum alanine (ALT) and aspartate aminotransferase (AST) activities were determined by a colorimetric method using a commercially available kit (Bioclin ${ }^{\circledR}$, Belo Horizonte, MG, Brazil) adapted to a multi-well plate spectrophotometer reader (Spectramax Plus ${ }^{\circledR}$, Molecular Devices, USA), and absorbance was registered at $505 \mathrm{~nm}$.

\section{Determination of mRNA levels}

mRNA was extracted from the liver tissue with TRI Reagent ${ }^{\circledR}$ and quantified using a Nanodrop ${ }^{\circledR}$ spectrophotometer while cDNA was synthesized using the High Capacity RNA-to-cDNA kit ${ }^{\circledR}$ (Applied Biosystems ${ }^{\circledR}$ ) and a $\mathrm{T} 100^{\mathrm{TM}}$ thermocycler $\left(\right.$ BioRad $\left.^{\circledR}\right)$. TaqMan ${ }^{\circledR}$ gene expression assays were purchased from Applied Biosystems ${ }^{\circledR}$ (Mm00487248_g1 for Cyp2a4/5, Mm00516007_m1 for hmox- 1 and 4352341E for $\beta$-actin, used as endogenous control). Real-time reactions were performed in a Step One Plus real-time thermocycler (Applied Biosystems ${ }^{\circledR}$ ). The relative quantification of the target genes was made using the Q-Gene software application (Equation 3 of the manuscript) [19].

\section{Statistical analysis}

Data following a normal distribution (e.g. enzyme activities) were analyzed by one-way analysis of variance (ANOVA) and Dunnett's post hoc test. For data that are known not to be normally distributed (e.g., percentages and ratios), the Kruskal-Wallis test was used, followed by the Mann-Whitney $U$ test with Bonferroni correction. Statistical evaluation was performed using GraphPad Prism version 5.01 for Windows (GraphPad Software, San Diego, California USA), and differences were considered statistically significant at a value of $\mathrm{P}<0.05$.

\section{Results and discussion}

\section{Interstrain differences in Cyp2a5 activity}

Results from this study showed that constitutive (non-induced) activity of $\mathrm{COH}$ in the liver microsomal fraction markedly varied among mouse strains $(\mathrm{P}<0.05$, ANOVA and Dunnett's post hoc test). The DBA-2 (D2) strain-the oldest of all inbred strains of mice-ranked first for $\mathrm{COH}$ activity (mean \pm SEM: $228.4 \pm 24.8 \mathrm{pmol} / \mathrm{mg} \mathrm{ptn} / \mathrm{min}$ ), while DBA-1 (D1) $(142.5 \pm 28.3 \mathrm{pmol} / \mathrm{mg} \mathrm{ptn} / \mathrm{min})$ exhibited the second highest activity. Of the remaining murine strains, $\mathrm{CBA}$, $\mathrm{BALB} / \mathrm{cAn}$ (BALB) and C57BL/6 (B6) presented $\mathrm{COH}$ activities ranging from $32.9 \pm 5.0$ to $44.5 \pm 6.0 \mathrm{pmol} /$ $\mathrm{mg} \mathrm{ptn} / \mathrm{min}$, while the lowest activities were found in C57BL/10 (B10) $(24.4 \pm 3.8 \mathrm{pmol} / \mathrm{mg} \mathrm{ptn} / \mathrm{min})$ and Swiss Webster (SW) mice $(24.1 \pm 5.3 \mathrm{pmol} /$ $\mathrm{mg} \mathrm{ptn} / \mathrm{min}$ ). Owing to its additive mode of inheritance, Cyp2a5 $(\mathrm{COH})$ activity in the liver of the hybrid B6D2F1 (F1) $(113.3 \pm 11.6 \mathrm{pmol} / \mathrm{mg} \mathrm{ptn} / \mathrm{min})$ was in between those of its parental high- (D2) and low- (B6) activity strains (Fig. 1; Table 1).

PYR $(100 \mathrm{mg} / \mathrm{kg}$ body weight/day i.p. $\times 3$ days $)$ enhanced $\mathrm{COH}$ activity in all strains (Table 1) with induction factors (IF: ratio of induced to non-induced activity) ranging from 2 to 2.5-fold for BALB, D2, D1 and B6 mice, and from 3.3 to 3.9 -fold for SW, CBA, B10 and F1 mice (see Additional file 1). The administration of PB $(80 \mathrm{mg} /$ $\mathrm{kg}$ body weight/day i.p. $\times 3$ days), a pleiotropic inducer of xenobiotic biotransformation enzymes, increased $\mathrm{COH}$ activity in all strains, except B6, D1 and SW (Table 1). The induction of $\mathrm{COH}$ by $\mathrm{PB}$, however, was less marked than that caused by PYR. Induction factors (IFs) after treatment with $\mathrm{PB}$ ranged from 2.1 to 2.8 -fold for BALB, D2, B10, F1 and CBA mice (see Additional file 1).

In summary, results indicated that $\mathrm{COH}$, a Cyp2a5mediated activity, varies up to 10 -fold between mouse strains. Notwithstanding the marked variation of constitutive activities, mice from all strains evaluated in this 


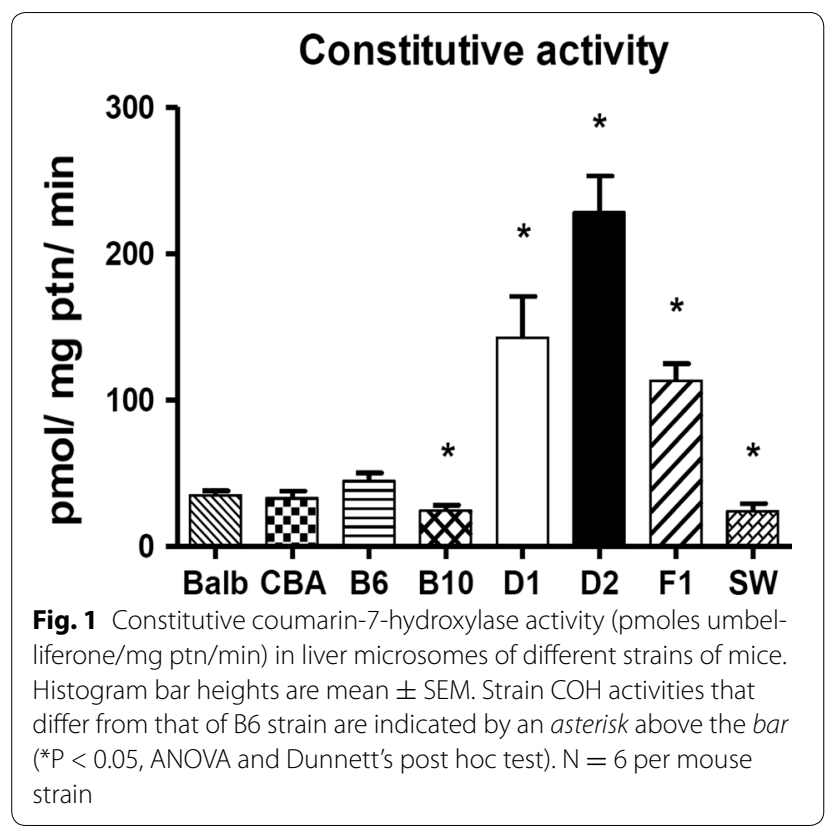

study responded to challenges with $\mathrm{PB}$ and PYR, a finding that suggests that constitutive strain-related differences do not involve xenoreceptors or mechanisms by which Cyp2a5-mediated activity is induced by xenobiotics. It is of note that $\mathrm{PB}$, a pleiotropic inducer of mice Cyp2a5, 2b9/10, 3a11 and other CYP isoforms, and PYR, an inducer of Cyp2a4, 2a5, 2e1 and 2j, enhance Cyp2a5catalyzed activities by distinct mechanisms [20-22].
Interstrain differences in Cyp1 a and Cyp2b activities Strain-related variations of Cyp1a1/2 (EROD) and Cyp2b9/10 (BROD) constitutive activities were far less pronounced than those observed with Cyp2a5 ( $\mathrm{COH})$ activity, and ratios of the highest to the lowest strain activity were 2.6 and 2.5fold for Cyp1a1/2 (B10 = $132.2 \pm 9.4 \mathrm{pmol} / \mathrm{mg}$ $\mathrm{ptn} / \mathrm{min} ; \mathrm{D} 1=50.2 \pm 3.3 \mathrm{pmol} / \mathrm{mg} \mathrm{ptn} / \mathrm{min})$ and Сyp2b9/10 $($ BALB $=56.6 \pm 5.7 \mathrm{pmol} / \mathrm{mg} \mathrm{ptn} / \mathrm{min}$; $\mathrm{CBA}=22.0 \pm 2.3 \mathrm{pmol} / \mathrm{mg} \mathrm{ptn} / \mathrm{min}$ ), respectively (Table 1).

PYR did not enhance Cyp1a1/2- and Cyp2b9/10-mediated activities in any mouse strain (i.e., IFs were nearly 1 ), a finding that is consistent with the notion that this heterocyclic diazole compound is a selective inducer of Cyp2a, 2j and Cyp2e1 activities in the liver tissue [22].

$\mathrm{PB}$, on the other side, markedly enhanced activities mediated by Cyp1a1/2 and Cyp2b9/10 in all mouse strains, thereby confirming that it causes a pleiotropic induction of hepatic monooxygenase activities. Treatment with $\mathrm{PB}$ provoked a nearly fourfold increase in Cyp1a1/2 activity (EROD) in all mouse strains, except for BALB, the IF of which was 7.5 (see Additional file 2). As far as induction of Cyp2b9/10 (BROD) is concerned, the effect of PB on CBA (9.7 fold), D1 (10.1 fold), F1 (8.7fold) and D2 (6.7 fold) was more pronounced than the effect on BALB, B6, B10 and SW $(3<\mathrm{IF}<5)$ (see Additional file 3). Chatuphonprasert et al. [23] also noted that inductions of EROD and BROD by PB in D2 were stronger than the inductions in $\mathrm{B} 6$ mice.

Table 1 Liver Cyp2a5 (COH), Cyp1a1/2 (EROD) and Cyp2b9/10 (BROD) activities in different mouse strains. Female mice were treated ip with PBS (CON), pyrazole (PYR $100 \mathrm{mg} / \mathrm{kg}$ bw/days $\times 3$ days), or phenobarbital (PB, $80 \mathrm{mg} / \mathrm{kg}$ bw/days $\times 3$ days) and euthanized 24-h after the last dose

\begin{tabular}{|c|c|c|c|c|c|c|c|c|c|}
\hline \multirow[t]{3}{*}{ Treatment } & \multicolumn{9}{|c|}{ Monooxygenase activity (pmoles/mg protein/min) } \\
\hline & \multicolumn{3}{|l|}{$\mathrm{COH}$} & \multicolumn{3}{|l|}{ EROD } & \multicolumn{3}{|l|}{ BROD } \\
\hline & CON & PYR & PB & CON & PYR & PB & CON & PYR & PB \\
\hline \multicolumn{10}{|l|}{ Mouse strain } \\
\hline $\mathrm{BALB} / \mathrm{CAn}$ & $35.2 \pm 2.9$ & $69.7 \pm 4.4^{*}$ & $75.3 \pm 6.0^{*}$ & $71.2 \pm 6.0$ & $103.1 \pm 9.0$ & $532.7 \pm 77.5^{*}$ & $56.6 \pm 5.7$ & $53.3 \pm 4.0$ & $192.8 \pm 23.9^{*}$ \\
\hline CBA & $32.9 \pm 5.0$ & $119.7 \pm 5.2^{*}$ & $91.9 \pm 5.4^{*}$ & $74.9 \pm 4.9$ & $61.5 \pm 5.5$ & $293.0 \pm 33.7^{*}$ & $22.0 \pm 2.3$ & $19.8 \pm 3.5$ & $212.5 \pm 22.4^{*}$ \\
\hline C57BL/6 & $44.5 \pm 6.0$ & $112.1 \pm 8.4^{*}$ & $62.2 \pm 5.5$ & $99.2 \pm 7.2$ & $98.7 \pm 8.6$ & $444.3 \pm 28.6^{*}$ & $47.3 \pm 5.8$ & $33.4 \pm 4.8$ & $158.9 \pm 8.7^{*}$ \\
\hline C57BL/10 & $24.4 \pm 3.8$ & $88.1 \pm 4.1^{*}$ & $63.6 \pm 5.9^{*}$ & $132.2 \pm 9.4$ & $135.5 \pm 16.9$ & $598.7 \pm 59.5^{*}$ & $42.6 \pm 3.5$ & $72.9 \pm 29.9$ & $181.3 \pm 5.5^{*}$ \\
\hline DBA-1 & $142.5 \pm 28.3$ & $344.8 \pm 50.6^{*}$ & $261.8 \pm 24.6$ & $50.2 \pm 3.3$ & $50.0 \pm 4.0$ & $265.7 \pm 13.1^{*}$ & $26.8 \pm 1.4$ & $43.4 \pm 12.4$ & $271.0 \pm 2.3^{*}$ \\
\hline DBA-2 & $228.4 \pm 24.8$ & $507.7 \pm 12.5^{*}$ & $493.5 \pm 11.7^{*}$ & $74.9 \pm 7.9$ & $64.3 \pm 6.3$ & $338.1 \pm 14.8^{*}$ & $39.8 \pm 2.8$ & $41.0 \pm 3.8$ & $266.9 \pm 28.5^{*}$ \\
\hline $\mathrm{B} 6 \mathrm{D} 2 \mathrm{~F} 1$ & $113.3 \pm 11.6$ & $437.8 \pm 24.3^{*}$ & $308.4 \pm 20.6^{*}$ & $68.8 \pm 3.4$ & $66.6 \pm 3.6$ & $251.1 \pm 14.1^{*}$ & $35.2 \pm 4.1$ & $45.0 \pm 5.3$ & $306.5 \pm 8.8^{*}$ \\
\hline SW & $24.1 \pm 5.3$ & $78.5 \pm 8.8^{*}$ & $42.5 \pm 3.1$ & $72.8 \pm 7.6$ & $74.8 \pm 9.1$ & $348.5 \pm 29.7^{*}$ & $41.2 \pm 7.8$ & $38.8 \pm 10.2$ & $143.6 \pm 4.4^{*}$ \\
\hline
\end{tabular}

Values are shown as mean \pm SEM. Data were evaluated by ANOVA and Dunnett's post hoc test. Means that are different $(P<0.05)$ from respective controls are indicated by an asterisk $\left(^{*}\right)$. $\mathrm{N}=6$ mice of each strain per group (CON, PYR or PB)

$\mathrm{COH}$ (coumarin 7-hydroxylase) pmoles umbelliferone/mg protein/min, $E R O D$ (ethoxyresorufin-), BROD (benzyloxy-resorufin-O-dealkylase) pmoles resorufin/mg protein/min 


\section{Interstrain differences in Cyp2a4/5 expression}

Cyp $2 a 4$ gene is highly related to Cyp $2 a 5$ ( $>98 \%$ identity in the amino acid sequences of their coding region) and both are expressed in the mouse liver. Despite their high degree of similarity, Cyp2a4 and Cyp2a5 genes code for enzymes that have distinct substrate specificities: while the former mediates 15 - $\alpha$-hydroxylation of steroid hormones (e.g., testosterone and estrogens), the latter catalyzes the 7-hydroxylation of coumarin. A single amino acid substitution (Phe209Leu) seems to be sufficient to convert the specificity of Cyp2a5 reaction from coumarin 7-hydroxylase to testosterone 15- $\alpha$-hydroxylase [24]. Primers and probe used in this study do not distinguish between the highly similar transcripts of Cyp $2 a 4$ and Cyp $2 a 5$, so that levels of both mRNAs were quantified jointly. As shown in Fig. 2, non-induced levels of Cyp2a4/5 mRNAs exhibited only minor inter-strain

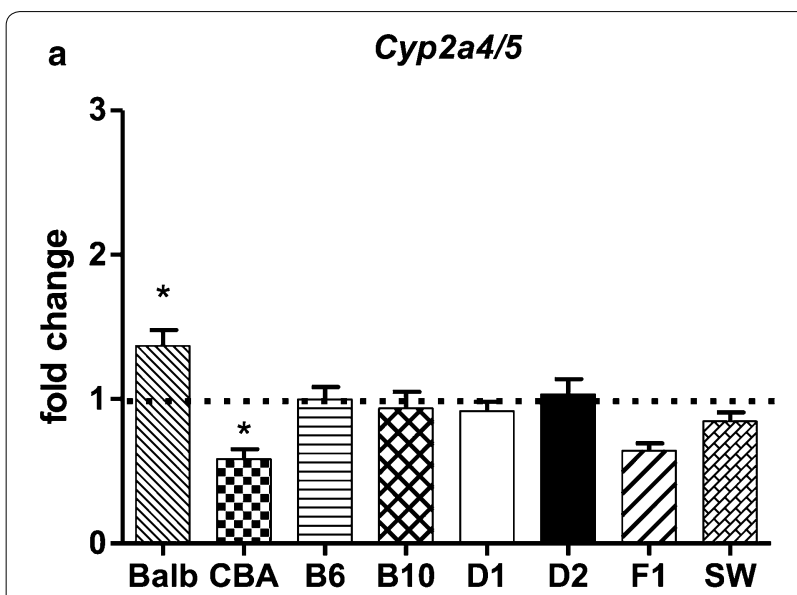

b

hmox-1

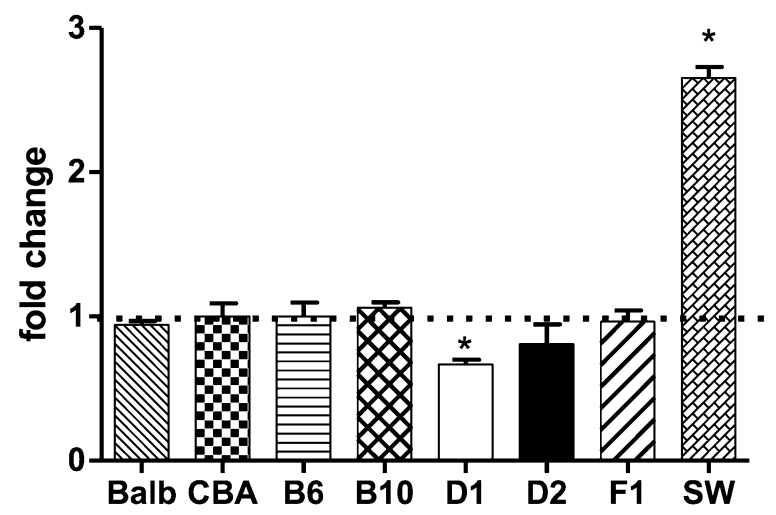

Fig. 2 Constitutive levels of Cyp2a4/5 and hmox-1 mRNA in the liver of mice from different strains. a (upper panel) expression of Cyp2a4/5. b (lower panel) expression of hmox-1. Relative quantification of mRNA was made by qPCR taking C57BL/6 liver sample as the reference ( ${ }^{*} \mathrm{P}<0.05$, Kruskal-Wallis test followed by Mann-Whitney $U$ test with Bonferroni's correction). $\mathrm{N}=6$ per mouse strain differences (Kruskal-Wallis test followed by MannWhitney $\mathrm{U}$ test, $\mathrm{P}<0.05$ when levels were compared to B6), a result that is at odds with the pronounced strain differences in constitutive levels of Cyp2a5-mediated activities $(\mathrm{COH})$ (Table 1). For instance, while constitutive activity of $\mathrm{COH}$ in D2 mice was nearly 10 -fold that found in SW, Cyp2a4/5 mRNA levels did not differ between the two strains. The induction of Cyp2a5 activity $(\mathrm{COH})$ by PYR, however, was accompanied by an elevation of Cyp2a4/5 mRNA levels in all mouse strains (Fig. 3). The effect of PB on Cyp2a4/5 mRNA was less evident than that of PYR. Although having enhanced Cyp2a4/5 expression in BALB/c, B6, D1, D2 and F1 mice, PB did not produce statistically significant elevations of Cyp2a4/5 mRNA over constitutive levels in CBA, B10 or SW strains (Fig. 3).

Using a PCR-enhanced diagnostic analysis based on Squires and Negishi's method [25], Hahnemann et al. [26] estimated the relative contributions of Cyp2a4 and Cyp2a5 to the total Cyp2a4/5 mRNA content in the liver of D2 and B6 male mice. The authors found that in both mouse strains, Cyp2a 5 mRNA represents nearly $90 \%$ of constitutive levels of total Cyp2a4/5 mRNA. Hahnemann et al. [26] also suggested that increases in the total Cyp2a4/5 mRNA produced by PYR were predominantly due to elevations in Cyp2a5 mRNA levels. This interpretation is also corroborated by data showing that PYR enhanced $\mathrm{COH}$ activity (Cyp2a5-mediated), but did not alter 15- $\alpha$-hydroxylase activity (Cyp2a4-mediated) in the D2 mice [26].

A number of studies demonstrated that liver Cyp2a5 can be induced by a myriad of structurally unrelated organic and inorganic chemicals such as PYR, $\mathrm{PB}, \mathrm{CCl}_{4}$, cocaine, griseofulvin, thioacetamide, metals such as cadmium, indium and cobalt and also by some infectious diseases such as hepatitis, malaria and fascioliasis $[8,9$, $27,28]$. The mechanisms by which chemical agents and infections induce Cyp2a5 are not entirely understood. It is generally accepted that induction of liver Cyp2a 5 activity and mRNA levels involves both transcriptional and post-transcriptional events [29]. The exact role played by several transcription factors (nuclear receptors) in the regulation of Cyp $2 a 5$ expression, however, is not completely elucidated.

Results presented here showed that PYR increased levels of total Cyp2a4/5 mRNA in all strains (Fig. 3), a finding that is consistent with those reported by other authors for D2 and B6 mice treated with this heterocyclic diazole compound $[26,30]$. It was described that the half-life of Cyp2a 5 mRNA in the liver of PYR-treated D2 mice was at least fourfold longer than that in untreated controls, an indication that increases in Cyp2a5 gene transcript levels were predominantly due to mRNA stabilization [30]. 


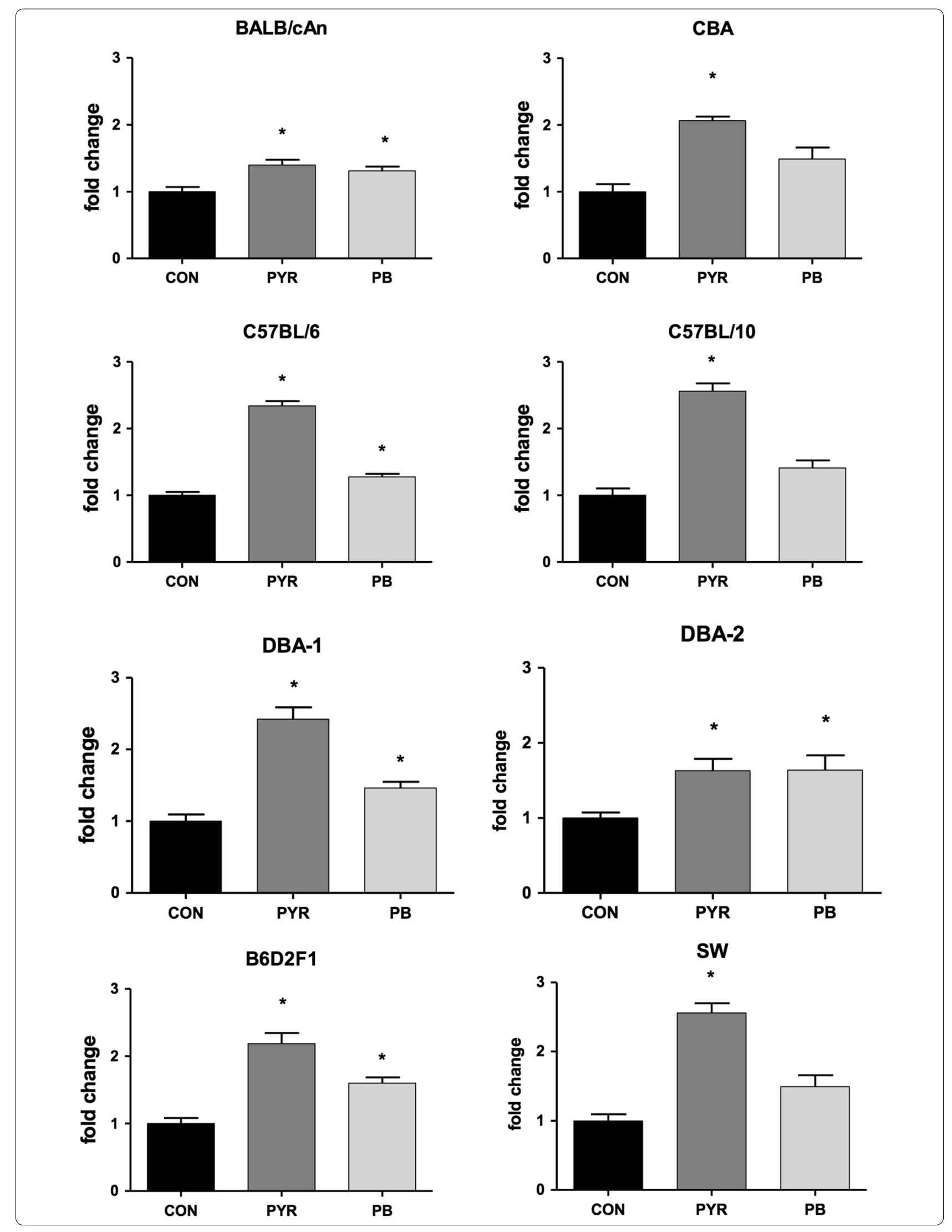


(See figure on previous page.)

Fig. 3 Pyrazole- and phenobarbital-induced expression of liver Cyp2a4/5 mRNAs in mice from different strains. Female mice were treated with phosphate buffered saline (CON, PBS $10 \mathrm{~mL} / \mathrm{kg}$ body weight/day $\times 3$ days, i.p), pyrazole (PYR, $100 \mathrm{mg} / \mathrm{kg}$ body weight/day $\times 3$ days, i.p.) or phenobarbital (PB, $80 \mathrm{mg} / \mathrm{kg}$ body weight/day $\times 3$ days, i.p.). Relative quantification of mRNA was made by qPCR taking the control mice (CON) as the reference. An asterisk $\left(^{*}\right)$ above the bar indicates that mRNA levels differ $(P<0.05$, Kruskal-Wallis test followed by Mann-Whitney $U$ test with Bonferroni's correction) from those of vehicle-controls $(C O N)$ of the same strain. $N=6$ mice of each strain per treatment group

Subsequent studies revealed that PYR increases the level of a heterogeneous nuclear riboprotein A1 (hnRNPA1) that binds to a 71-nucleotide region of Cyp2a5 mRNA, thereby protecting it from degradation $[20,31,32]$. These studies strongly suggested that induction of liver Cyp2a 5 by PYR is a mainly post-transcriptional and pre-translational event that involves Cyp2a5 mRNA stabilization. The mechanism by which PYR and related compounds produce alterations of Cyp2a 5 mRNA-binding proteins, however, is not entirely understood.

The induction of Cyp2a5 by $\mathrm{PB}$, on the other side, seems to involve enhanced translational efficiency and/or protein stabilization in addition to increased transcription rates. For instance, while increasing Cyp2a protein and Cyp2a5 activity $(\mathrm{COH}), \mathrm{PB}$ did not change levels of Cyp2a4/5 mRNA in the liver of male D2 mice [30]. Nonetheless, Hahnemann et al. [26] reported that PB enhanced Cyp2a4/5 mRNA and Cyp2a5 activity by 2- to 3 -fold in the liver of C57BL/6 mice. In the present study, while increasing Cyp2a 5 activity $(\mathrm{COH})$ by 2 - to 3 -fold in most strains (Table 1$)$, PB produced only a slight $(<$ twofold) increase in Cyp2a4/5 mRNA levels (Fig. 3).

The most striking finding of the interstrain comparison was that, while presenting much higher constitutive activities of Cyp2a5 (Table 1), D2 and D1 (and also the hybrid B6D2F1) did not exhibit levels of Cyp2a4/5 mRNA more elevated than those found in the remaining mouse strains (Fig. 2).

It is known that some xenobiotic metabolizing enzyme mRNAs do not correlate well with protein expression and consequently with enzyme activities. Chang et al. [33], for instance, found that CYP1A2 mRNA and protein (immunoblot analysis) levels were not correlated in human liver samples. Along the same line, Ohtsuki et al. [34] reported that human liver CYP1A2, CYP2A6, CYP2C9, CYP2E1 and CYP4A11 correlated poorly whereas other CYPs correlated highly (CYP2B6, CYP2C8, CYP3A4) or moderately (CYP2C9, CYP2D6, CYP3A5, CYP3A7) with protein (quantified by LC/MS/ MS analysis) expression levels. Ohtsuki et al. [34] also noted that, for most CYPs, there was a better correlation of enzyme activities to protein levels than to mRNAs levels. The reasons why mRNAs of some human liver CYPs including CYP2A6 did not correlate well with protein expression are unclear.
In principle, increased enzyme activity when mRNAs levels remain unchanged could be explained either because of protein stabilization (which increases protein levels) or due to post-translational/allosteric mechanisms (which do not alter protein levels). Since we did not quantify protein levels in the present study, it was not possible to exclude one of these two explanations for the inter-strain differences in the constitutive activity of Cyp2a5. The interpretation that inter-strain differences in Cyp2a5 activity might result from differences in degree of protein stabilization (and protein levels), however, is consistent with enzyme kinetic data provided by other studies. Although $\mathrm{COH} \mathrm{V}$ max determined in liver microsomes from D2 was higher than that measured in microsomes from $A K R$ and $C 57 \mathrm{BL} / 6$, the reaction $\mathrm{K}_{\mathrm{m}}$ did not differ either between D2 and AKR [35], or between D2 and B6 strains [36]. Since $K_{m}$ was essentially the same, strain distinct $\mathrm{COH}$ constitutive activities should result from different amounts of Cyp2a5 protein in liver microsomes. As far as the authors are aware, no previous study has compared the constitutive levels of Cyp2a4/5 (or Cyp2a5) mRNAs between mouse strains using a quantitative realtime PCR method (qPCR). The lack of quantitative data on the Cyp2a5 protein expression levels in the evaluated mouse strains, however, is an important limitation of this study.

\section{Hepatotoxicity and Cyp2a5 induction}

Since Cyp2a5 expression and activity are up-regulated by hepatotoxic agents and some liver pathological conditions $[8,9]$, it was postulated that oxidative stress or another pathophysiological change associated with liver injury may eventually elicit Cyp $2 a 5$ overexpression [6, 37]. PYR is hepatotoxic and dose regimens of this heterocyclic compound that cause strong inductions of Cyp2a5 also produce a marked elevation of serum aminotransferases (ALT and AST), a marker for liver damage, as demonstrated after treatment with one single injection of $200 \mathrm{mg} / \mathrm{kg} \mathrm{bw} /$ days [6], $150 \mathrm{mg} / \mathrm{kg}$ bw/days $\times 2$ days [38] or one single injection of $100 \mathrm{mg} / \mathrm{kg}$ bw of PYR [6]. In the present study, statistical analysis (Kruskal-Wallis test followed by Mann-Whitney U test, $\mathrm{P}<0.05)$ showed a modest (<twofold) increase of ALT in CBA (IF = 1.6) and B10 (IF = 1.8) treated with PYR. ALT serum levels remained unaltered in $\mathrm{PB}$-treated mice (Fig. 4). AST 

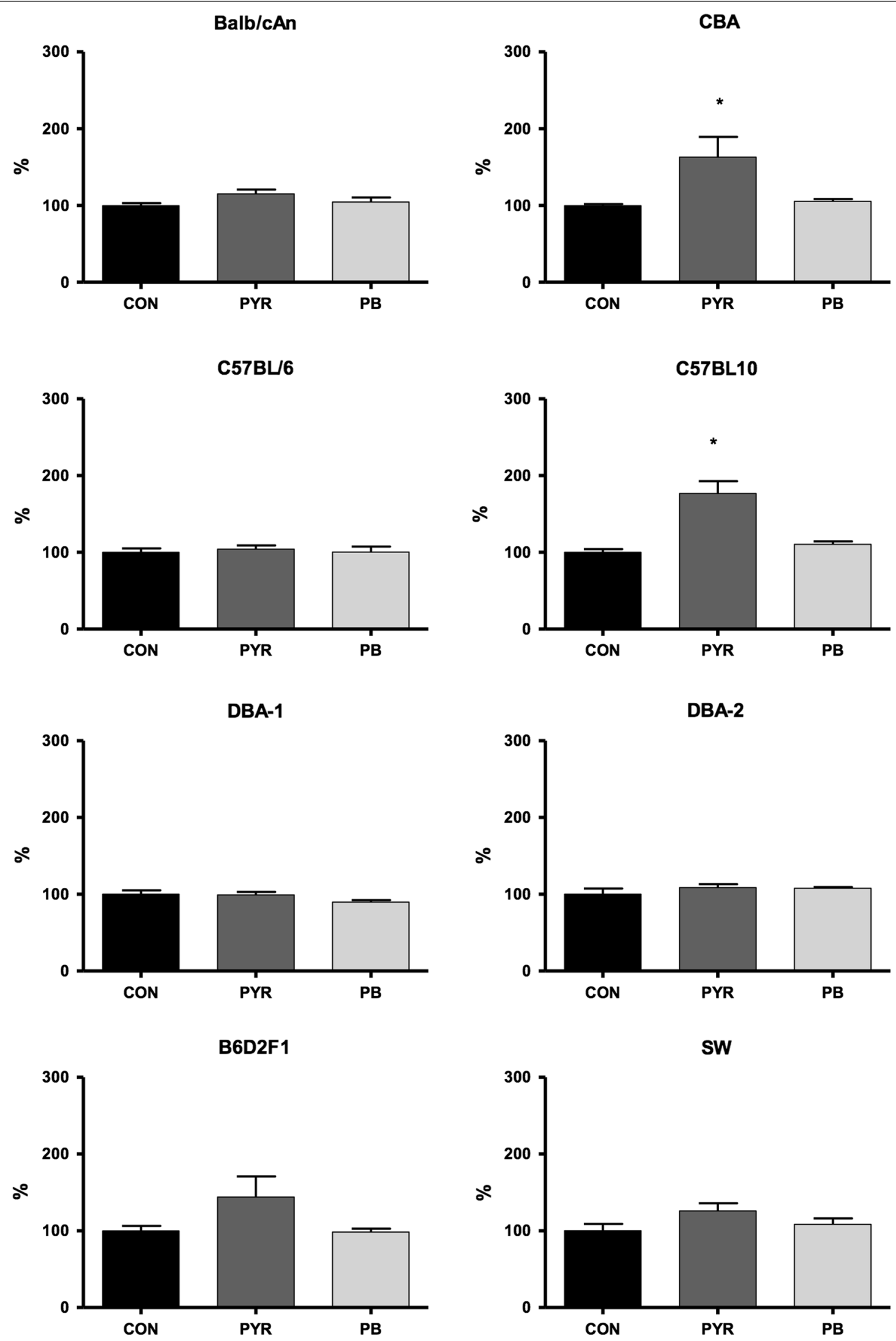
(See figure on previous page.)

Fig. 4 Interstrain differences in serum levels of ALT after treatment with pyrazole or phenobarbital. ALT serum levels (IU/L) in BALB/C, CBA, B6, B10, D1, D2, F1 and SW mice treated with phosphate buffered saline (CON, PBS $10 \mathrm{~mL} / \mathrm{kg}$ body weight/day $\times 3$ days, i.p), pyrazole- (PYR, $100 \mathrm{mg} / \mathrm{kg}$ body weight/day $\times 3$ days, i.p.) or phenobarbital (PB, $80 \mathrm{mg} / \mathrm{kg}$ body weight/day $\times 3$ days, i.p.). ALT serum levels are expressed as ratio of PYR- or PB-treated to average control group levels (100\%). ${ }^{*}$ levels are different from those of vehicle controls (CON) of the same strain (P $<0.05$, KruskalWallis test followed by Mann-Whitney $U$ test with Bonferroni's correction). $N=6$ mice of each strain per treatment group

was not altered in PYR treated mice. Except for a small elevation (<twofold) of AST serum levels in B10 and D2 mice, AST was not altered by administration of PB either (Additional file 4). Therefore, the dose regimen of PYR $(100 \mathrm{mg} / \mathrm{kg}$ bw/days $\times 3$ days) chosen for this study was sufficient to up-regulate Cyp2a5 expression and activity without causing clinically evident liver injury.

Concomitant induction of $h m o x-1$ and Cyp2a4/5 expression Some authors postulated that all pathophysiological conditions and hepatotoxic chemicals that up-regulate Cyp2a5 share the common feature of altering cellular redox state in the liver tissue $[37,39,40]$. Along this line, it was suggested that Nrf2, a transcription factor regulated at the post-transcription level by oxidative stress, plays a key role in the induction of Cyp2a 5 by agents and conditions that eventually lead to liver damage. Nfr2 also mediates the expression of a set of redox homeostasis genes including hmox-1 [40] and concomitant inductions of liver Cyp2a 5 and hmox-1 in D2 mice intoxicated with $\mathrm{Cd}$ [41] and in those infected with malaria parasites [9] were reported. Enhanced hmox-1 activity results in increased production of bilirubin, the accumulation of which is potentially toxic. If Cyp2a 5 is in fact involved in the oxidation of bilirubin, as suggested by Abu-Bakar et al. [41], a concurrent up-regulation of hmox-1 and Cyp2a5 in some toxic and pathological conditions, by maintaining a balance between bilirubin production and elimination, would confer a certain protection against liver damage caused by enhanced oxidative stress.

Data from this study, however, showed that PYR, at a dose regimen that induced Cyp2a5 activity (and Cyp2a4/5 mRNA expression) in the absence of signs of hepatotoxicity, failed to enhance hmox-1 expression in the livers of BALB, CBA, B6, B10, D2, F1 and SW mice (Fig. 5). Nichols and Kirby [42] found an enhanced expression of hmox-1 (micro-array analysis confirmed with q-RT-PCR) in the liver of B6 mice 24-h after treatment with a high dose of PYR (200 mg/kg bw, ip). Unlike the PYR dose regimen used in our study $(100 \mathrm{mg} / \mathrm{kg} \mathrm{bw} / \mathrm{d}$ ays $\times 3$ days), the PYR dose employed by Nichols and Kirby [42] induced a marked rise in ALT serum levels.

Differences in the response of hmox-1 and Cyp2a5 to treatment with $\mathrm{PbCl}_{2}$ and $\mathrm{MeHg}$ were observed in mouse primary hepatocytes [40]. Although $\mathrm{Pb}$ and $\mathrm{Hg}$ activated
Nfr2 and enhanced both hmox-1 and Cyp2a5 expression, the up-regulation of $h m o x-1$ gene was more rapid and transient as compared to that of $C y p 2 a 5$. Moreover, contrasting with a lack of induction of Cyp $2 a 5$ expression, an enhanced expression of $h m o x-1$ was still present in hepatocytes from Nfr2 null mice [40]. According to the authors, a possible explanation for the aforementioned differences could be an involvement of the transcriptional repressor Bach 1 in the regulation of $h m o x-1$ gene. In other words, while Nfr2 would be critical for regulating Cyp2a5 in any case, inactivation of Bach 1 would induce hmox-1 in the Nfr2 null mouse.

\section{Conclusions}

In conclusion, results from this study showed that constitutive activity of Cyp2a5 $(\mathrm{COH})$ in the liver of D2 and D1 were clearly higher than that of the outbred SW or the inbred strains BALB, CBA, B6 and B10. As expected from an additive mode of inheritance, Cyp2a5 activity of the hybrid B6D2F1 was intermediate between those of its high- and low-activity parents (DBA-2 and C57BL/6, respectively). Since background levels of Cyp2a4/5 gene transcripts of high-activity strains (D1, D2) did not differ from those of low-activity mice (e.g., SW, B6, B10), distinct constitutive activities did not result from different transcription rates and/or mRNA half-lives. The absence of data on Cyp2a 5 protein levels was an important limitation of this study. Owing to the lack of quantitative data on protein expression levels it was not possible to elucidate whether constitutive activities of Cyp2a5 correlated with protein levels. Differences in protein stabilization and/or in post-translational/allosteric mechanisms are possible explanations for strain differences in Cyp2a5 constitutive activity.

It was also shown that PYR up-regulated Cyp2a5 activity and Cyp $2 a 4 / 5$ expression, but did not affect Cyp1a1/2 and Cyp2b9/10 activities in the liver of mice from any strain. As expected from a pleiotropic inductor, $\mathrm{PB}$ increased activities of Cyp2a5, Cyp1a1/2 and Cyp2b9/10 as well. In CBA, B10 and SW PB-caused induction of Cyp2a5 activity was unaccompanied by a clear enhancement of Cyp2a4/5 mRNA levels, a finding that is consistent with the prevailing notion that $\mathrm{PB}$-mediated CYP2A induction involves mainly actions at translational and/ or post-translational levels (Fig. 3). Finally, Cyp2a5 


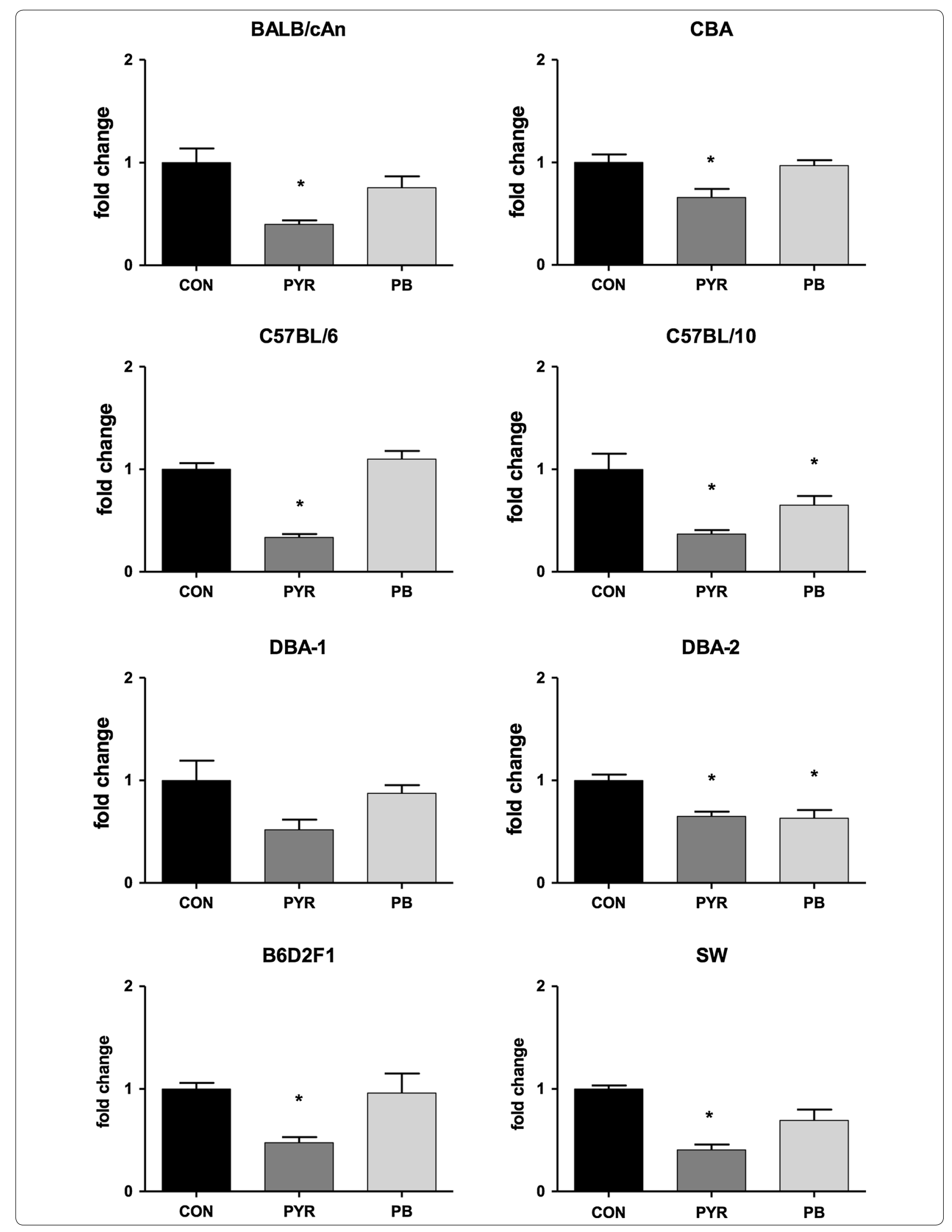


(See figure on previous page.)

Fig. 5 Pyrazole and phenobarbital induced expression of liver hmox-1 mRNAs in mice from different strains. Female mice were treated with phosphate buffered saline (CON, PBS $10 \mathrm{~mL} / \mathrm{kg}$ body weight/day $\times 3$ days, i.p), pyrazole (PYR, $100 \mathrm{mg} / \mathrm{kg}$ body weight/day $\times 3$ days, i.p.) or phenobarbital (PB, $80 \mathrm{mg} / \mathrm{kg}$ body weight/day $\times 3$ days, i.p.). Relative quantification of mRNA was made by qPCR taking the control mice (CON) as the reference. An asterisk $\left(^{*}\right)$ above the bar indicates that mRNA levels differ $(\mathrm{P}<0.05$, Kruskal-Wallis test followed by Mann-Whitney $\mathrm{U}$ test with Bonferroni's correction) from those of vehicle-controls (CON) of the same strain. $N=6$ mice of each strain per treatment group

up-regulation by PYR, a known hepatotoxin, was unaccompanied by clinical signs of liver toxicity with the dose used in this study, a result that differs from the results observed by Gilmore et al. [6]. In this study, PYR and PB did not up-regulate hmox-1 mRNA, a finding that is at odds with the idea that Cyp2a5 and hmox-1 inductions are associated events that share a common Nfr2-activation pathway.

\section{Additional files}

Additional file 1. Inter-strain differences in the induction of liver $\mathrm{COH}$ activity by pyrazole and phenobarbital.

Additional file 2. Inter-strain differences in the liver EROD activity.

Additional file 3. Inter-strain differences in the liver BROD activity.

Additional file 4. AST in the serum of mice treated with PYR or PB.

\section{Abbreviations}

ALT: alanine aminotransferase; AST: aspartate aminotransferases; BROD: benzyloxyresorufin-O-debenzylase; bw: body weight; $\mathrm{COH}$ : coumarin

7-hydroxylase; EROD: ethoxyresorufin-O-deethylase; hmox-1: heme oxygenase 1; IF: induction factor; LC/MS/MS: liquid chromatography/tandem mass spectrometry; LMF: liver microsomal fraction; Mouse strains: D1, DBA-1; D2, DBA-2; B6, C57BL/6; B10, C57BL/10; F1, F1 hybrid of C57BL/6 female and DBA-2-male; SW: Swiss Webster; NfR2: nuclear factor (erythroid-derived 2)-like 2 (also know as NEFE2L2); PB: phenobarbital; PYR: pyrazole; qPCR: real-time polymerase chain reaction.
\end{abstract}

\section{Authors' contributions}

ACAXO conceived the study, its design and supervised the performance of biochemical assays at the bench. KSP performed animal treatment and all the biochemical assays. KSP, LFC, BSL and HSL prepared liver microsomal fractions. TEMP conceived the GPCR design and together with KSP performed the reactions. ACAXO and FJRP supervised the statistical analysis, its interpretation and worked together in drafting the manuscript. All authors read and approved the final manuscript.

\section{Acknowledgements}

Not applicable.

\section{Competing interests}

The authors declare that they have no competing interests.

\section{Availability of data and materials}

All data supporting study findings are within the manuscript. Additional detailed information and raw data are available and will be shared upon request addressed to the corresponding author.

\section{Ethics approval and consent to participate}

We declare that the study was approved by the Ethics Committee on the use of Animals (CEUA) of the Oswaldo Cruz Foundation (FIOCRUZ).

\section{Funding}

This study was supported by the INOVA-ENSP (Programme for Supporting Research and Innovation in Health Sciences-National School of Public Health—FIOCRUZ, RJ) grant. KSP (PhD student) and FJRP (senior researcher) were the recipients of fellowships awarded by CAPES (Coordination for the Improvement of Higher Level_or Education_Personnel) and CNPq (Brazilian National Research Council).

Received: 20 October 2015 Accepted: 22 February 2017

Published online: 15 March 2017

\section{References}

1. Wang H, Donley KM, Keeney DS, Hoffman SM. Organization and evolution of the Cyp2 gene cluster on mouse chromosome 7, and comparison with the syntenic human cluster. Environ Health Perspect. 2003;111(15):1835-42.

2. Su T, Ding X. Regulation of the cytochrome P450 2A genes. Toxicol Appl Pharmacol. 2004;199(3):285-94.

3. Kirby GM, Nichols KD, Antenos M. CYP2A5 induction and hepatocellular stress: and adaptive response to perturbations of heme homeostasis. Curr Drug Metab. 2011;12:186-97.

4. Kobliakov V, Kulikova L, Samoilov D, Lang MA. High expression of cytochrome P450 2a-5 (coumarin 7-hydroxylase) in mouse hepatomas. Mol Carcinog. 1993;7(4):276-80.

5. Chomarat P, Sipowicz MA, Diwan BA, Fornwald LW, Awasthi YC, Anver MR, Rice JM, Anderson LM, Wild CP. Distinct time courses of increase in cytochromes P450 1A2, 2A5 and glutathione S-transferases during the progressive hepatitis associated with Helicobacter hepaticus. Carcinogenesis. 1997;18(11):2179-90.

6. Gilmore WJ, Hartmann G, Piquette-Miller M, Marriott J, Kirby GM. Effects of lipopolysaccharide-stimulated inflammation and pyrazole-mediated hepatocellular injury on mouse hepatic Cyp2a5 expression. Toxicology. 2003;184(2-3):211-26.

7. Conte FP, Fidalgo-Neto AA, Manhães-Rocha DA, Paumgartten FJ, DeOliveira AC. Activity of liver microsomal enzymes during the chronic phase of murine schistosomiasis. Braz J Med Biol Res. 2007;40(5):657-62.

8. De-Oliveira AC, Da-Matta AC, Paumgartten FJ. Plasmodium berghei (ANKA): infection induces CYP2A5 and 2E1 while depressing other CYP isoforms in the mouse liver. Exp Parasitol. 2006;113(4):256-61.

9. De-Oliveira AC, Carvalho RS, Paixão FH, Tavares HS, Gueiros LS, Siqueira CM, Paumgartten FJ. Up- and down-modulation of liver cytochrome P450 activities and associated events in two murine malaria models. Malar J. 2010;9:81.

10. Wood AW, Conney AH. Genetic variation in coumarin hydroxylase activity in the mouse (Mus musculus). Science. 1974;185(4151):612-4

11. van lersel M, Walters DG, Price RJ, Lovell DP, Lake BG. Sex and strain differences in mouse hepatic microsomal coumarin 7-hydroxylase activity. Food Chem Toxicol. 1994;32(4):387-90.

12. Lovell DP, van lersel M, Walters DG, Price RJ, Lake BG. Genetic variation in the metabolism of coumarin in mouse liver. Pharmacogenetics. 1999;9(2):239-50.

13. Wood AW, Taylor BA. Genetic regulation of coumarin hydroxylase activity in mice. Evidence for single locus control on chromosome. J Biol Chem. 1979;254(13):5647-51.

14. Raunio H, Syngelmä T, Pasanen M, Juvonen R, Honkakoski P, Kairaluoma MA, Sotaniemi E, Lang MA, Pelkonen O. Immunochemical and catalytical studies on hepatic coumarin 7-hydroxylase in man, rat, and mouse. Biochem Pharmacol. 1988;37(20):3889-95. 
15. National Research Council (US) Committee for the Update of the Guide for the Care and Use of Laboratory Animals. Guide for the Care and Use of Laboratory Animals. 8th ed; 2011. Accessed 12 Feb 2013. http://grants. nih.gov/grants/olaw/Guide-for-the-Care-and-use-of-laboratory-animals. pdf.

16. De-Oliveira AC, Ribeiro-Pinto LF, Paumgartten JR. In vitro inhibition of CYP2B1 monooxygenase by beta-myrcene and other monoterpenoid compounds. Toxicol Lett. 1997;92(1):39-46.

17. Bradford MM. A rapid and sensitive method for the quantitation of microgram quantities of protein utilizing the principle of protein-dye binding. Anal Biochem. 1976;1976(72):248-54.

18. Kennedy SW, Jones SP. Simultaneous measurement of cytochrome P4501A catalytic activity and total protein concentration with a fluorescence plate reader. Anal Biochem. 1994;222(1):217-23.

19. Muller PY, Janovjak H, Miserez AR, Dobbie Z. Processing of gene expression data generated by quantitative real-time RT-PCR. Biotechniques. 2002;32(6):2-7.

20. Geneste $\mathrm{O}$, Raffalli F, Lang MA. Identification and characterization of a $44 \mathrm{kDa}$ protein that binds specifically to the $3^{\prime}$-untranslated region of CYP2a5 mRNA: inducibility, subcellular distribution and possible role in mRNA stabilization. Biochem J. 1996;313(Pt 3):1029-37.

21. Ueda K, Hamadeh Hisham K, Webb Heather K, Yamamoto Y, Sueyoshi T, Afshari Cynthia A, Lehmann Jürgen M, Negishi M. Diverse roles of the nuclear orphan receptor CAR in regulating hepatic genes in response to phenobarbital. Mol Pharmacol. 2002;61:1-6.

22. Franzén A, Carlsson C, Hermansson V, Lang M, Brittebo EB. CYP2A5-mediated activation and early ultrastructural changes in the olfactory mucosa: studies on 2,6-dichlorophenyl methylsulfone. Drug Metab Dispos. 2006;34(1):61-8.

23. Chatuphonprasert $W$, Rermraksakul $P$, Udomsuk L, Lao-ong $T$, Jarukamjorn K. Different profiles of hepatic alkoxyresorufin $O$-dealkylase activities in small rodents. J Appl Toxicol. 2012;32(12):1002-7.

24. Negishi M, Uno T, Honkakoski P, Sueyoshi T, Darden TA, Pedersen LP. The roles of individual amino acids in altering substrate specificity of the P450 2a4/2a5 enzymes. Biochimie. 1996;78(8-9):685-94.

25. Squires EJ, Negishi M. Reciprocal regulation of sex-dependent expression of testosterone 15 alpha-hydroxylase (P-450 (15 alpha)) in liver and kidney of male mice by androgen. Evidence for a single gene. J Biol Chem. 1988;263(9):4166-71.

26. Hahnemann B, Salonpää P, Pasanen M, Mäenpää J, Honkakoski $P$, Juvonen $\mathrm{R}$, Lang M, Pelkonen $\mathrm{O}$, Raunio H. Effect of pyrazole, cobalt and phenobarbital on mouse liver cytochrome P-450 2a-4/5 (Cyp2a-4/5) expression. Biochem J. 1992;286(Pt 1):289-94.

27. Kirby GM, Chemin I, Montesano R, Chisari FV, Lang MA, Wild CP. Induction of specific cytochrome P450s involved in aflatoxin B1 metabolism in hepatitis B virus transgenic mice. Mol Carcinog. 1994;11:74-80.

28. Montero R, Gentile GJ, Frederick L, McMannis J, Murphy T, Silva G, Blankespoor H, Gentile JM. Induced expression of CYP2A5 in inflamed trematode-infested mouse liver. Mutagenesis. 1999;14:217-20.
29. Abu-Bakar A, Hakkola J, Juvonen R, Rahnasto-Rilla M, Raunio H, Lang MA. Function and regulation of the Cyp2a5/CYP2A6 genes in response to toxic insults in the liver. Curr Drug Metab. 2013;14(1):137-50.

30. Aida K, Negishi M. Posttranscriptional regulation of coumarin 7-hydroxylase induction by xenobiotics in mouse liver: mRNA stabilization by pyrazole. Biochemistry. 1991;30(32):8041-5.

31. Tilloy-Ellul A, Raffalli-Mathieu F, Lang MA. Analysis of RNA-protein interactions of mouse liver cytochrome P4502A5 mRNA. Biochem J. 1999:339:695-703.

32. Raffalli-Mathieu F, Glisovic T, Ben-David Y, Lang MA. Heterogeneous nuclear ribonucleoprotein $\mathrm{A} 1$ and regulation of the xenobiotic-inducible gene Cyp2a5. Mol Pharmacol. 2002;61(4):795-9.

33. Chang TK, Chen J, Pillay V, Ho JY, Bandiera SM. Real-time polymerase chain reaction analysis of CYP1B1 gene expression in human liver. Toxicol Sci. 2003;71(1):11-9.

34. Ohtsuki S, Schaefer O, Kawakami H, Inoue T, Liehner S, Saito A, Ishiguro N, Kishimoto W, Ludwig-Schwellinger E, Ebner T, Terasaki T. Simultaneous absolute protein quantification of transporters, cytochromes P450, and UDP-glucuronosyltransferases as a novel approach for the characterization of individual human liver: comparison with mRNA levels and activities. Drug Metab Dispos. 2012;40(1):83-92.

35. Lang $M A$, Juvonen $R$, Järvinen $P$, Honkakoski $P$, Raunio $H$. Mouse liver P450Coh: genetic regulation of the pyrazole-inducible enzyme and comparison with other P450 isoenzymes. Arch Biochem Biophys. 1989;271(1):139-48

36. Pelkonen O, Sotaniemi EA, Ahokas JT. Coumarin 7-hydroxylase activity in human liver microsomes. Properties of the enzyme and interspecies comparisons. Br J Clin Pharmacol. 1985;19(1):59-66.

37. Gilmore WJ, Kirby GM. Endoplasmic reticulum stress due to altered cellular redox status positively regulates murine hepatic CYP2A5 expression. J Pharmacol Exp Ther. 2004;308(2):600-8.

38. LuY, Gong P, Cederbaum Al. Pyrazole induced oxidative liver injury independent of CYP2E1/2A5 induction due to Nrf2 deficiency. Toxicology. 2008;252:9-16.

39. Abu-Bakar A, Lämsä V, Arpiainen S, Moore MR, Lang MA, Hakkola J. Regulation of CYP2A5 gene by the transcription factor nuclear factor (erythroid-derived 2)-like 2. Drug Metab Dispos. 2007;35(5):787-94.

40. Lämsä V, Levonen $\mathrm{AL}$, Leinonen $\mathrm{H}$, Ylä-Herttuala S, Yamamoto M, Hakkola J. Cytochrome P450 2A5 constitutive expression and induction by heavy metals is dependent on redox-sensitive transcription factor Nrf2 in liver. Chem Res Toxicol. 2010;23(5):977-85.

41. Abu-Bakar A, Moore MR, Lang MA. Evidence for induced microsomal bilirubin degradation by cytochrome P450 2A5. Biochem Pharmacol. 2005:70:527-35.

42. Nichols KD, Kirby GM. Microarray analysis of hepatic gene expression in pyrazole-mediated hepatotoxicity: identification of potential stimuli of Cyp2a5 induction. Biochem Pharmacol. 2008;75(2):538-51.

\section{Submit your next manuscript to BioMed Central and we will help you at every step:}

- We accept pre-submission inquiries

- Our selector tool helps you to find the most relevant journal

- We provide round the clock customer support

- Convenient online submission

- Thorough peer review

- Inclusion in PubMed and all major indexing services

- Maximum visibility for your research

Submit your manuscript at www.biomedcentral com/submit
BioMed Central 